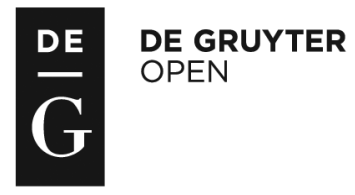

Administration, vol. 63, no. 2 (2015), pp. 177-190

doi: 10.1515/admin-2015-0015

\title{
A case study of the Tipperary County Council merger
}

\author{
Joanna O'Riordan \\ Institute of Public Administration
}

\section{Introduction}

This paper reviews the merger of the former North and South Tipperary County Councils, which took place in June 2014. The merger happened within the context of an extensive programme of public service cost reduction and also the announcement of the local government reform programme Putting People First (Department of Environment, Community and Local Government, 2012) and the subsequent Local Government Reform Act, 2014. Combined with the latter the merger represented a major reform of local government arrangements in Tipperary.

The report from which this paper is drawn recognises at the outset that it is too early to reach definitive conclusions with respect to the longer-term impact of the merger. Within this context, the objectives of the review were threefold:

i. to document the merger process;

ii. to review outcomes to date;

iii. to inform Tipperary County Council with regard to issues that require attention to ensure long-term consolidation within the new authority. 
It was further anticipated that, in meeting these objectives, the report would provide learning to other public service organisations engaged in reorganisation.

The research in relation to the case study was carried out in autumn 2014. The findings were drawn from a review of the literature and from consultations with the merger implementation team; senior managers across the council, including retired senior managers; trade union officials; staff focus groups; and elected representatives.

The main research shows globally that about two out of three mergers or acquisitions fail. In this regard a comment made by Professor Cary Cooper (quoted in Grant Thornton, 2010) is instructive because he emphasises that 'by failure I don't mean the company or the organisation goes bankrupt or disappears entirely, but they don't get what they anticipated. In other words, they anticipated two plus two should equal five - but it ends up being more like three.' Ongoing monitoring and willingness to accept adjustments and adaptations are therefore critical to all merger consolidations.

\section{Background}

The general trend across OECD countries since the early 2000s has been towards fewer, larger local authorities, though the benefits of this trend are far from certain (Boyle, 2015). The reason put forward for merger and amalgamation is generally that they represent an effective method of enhancing the operational efficiency of local councils, improve their administrative and technical capacity, generate cost savings, strengthen strategic decision-making and foster greater political power. By contrast, opponents of consolidation typically underline the divisive nature of amalgamations, the absence of supportive empirical evidence, the equivocal outcomes observed in case studies and the diminution of local democracy (Dollery \& Kortt, 2013, p. 74).

In Ireland, in response to the collapse of the economy and the need to reduce public service spending, the Report of the Local Government Efficiency Review Group (Government of Ireland, 2010) made wideranging recommendations to achieve efficiency gains and savings in local government. One of the recommendations involved the city and county councils in Limerick and Waterford and the two county councils in Tipperary merging. However, unlike in Limerick and 
Waterford, where there was a consultation process to explore different reorganisation options prior to the decision to merge, in the case of Tipperary the decision was made directly by government, and announced in July 2011.

\section{The context behind the Tipperary merger}

- The Public Service (Croke Park) Agreement (June 2010);

- Report of the Local Government Efficiency Review Group (July 2010);

- Announcement of merger of North and South Tipperary County Councils (July 2011);

- Public Service Reform (November 2011);

- Final Report of the Local Government/Local Development Alignment Steering Group (March 2012);

- Acceptance by the Minister for the Environment, Community and Local Government of the Tipperary merger implementation plan (July 2012);

- Putting People First: Action Programme for Effective Local Government (October 2012);

- Local Electoral Area Boundary Committee Report (May 2013);

- Haddington Road Agreement (May 2013);

- Incorporation of Irish Water as a semi-state company (July 2013);

- The Local Government Reform Act (January 2014);

- County Enterprise Boards (Dissolution) Act (March 2014);

- Establishment of local enterprise offices under the auspices of local authorities (April 2014);

- Local government elections (May 2014);

- Establishment of Tipperary County Council and first meeting of new council (June 2014).

\section{Merger planning}

The merger planning phase encompassed the period from the establishment of the government-appointed Tipperary Reorganisation Implementation Group (TRIG) in July 2011 through to the acceptance in July 2012 by the Minister for the Environment, Community and Local Government of the merger implementation plan. The TRIG had a general mandate to oversee planning, preparatory work and initial implementation of the merger process. The group included the two county managers and external experts.

From the outset of the project it was recognised by those involved that the merger of two county local authorities presented significant 
challenges. Many of these were identified in the project terms of reference, with the implementation group required to have oversight in respect of a number of key areas, including the provision of information to, and consultation with, the elected councils, the impact of the merger on a wide range of other organisations connected with local government, and the importance from the government's perspective of maximising cost reductions and efficiencies.

From a practical perspective, the merging of two councils whose principal centres were located ninety kilometres and one and a half hours of travel time apart represented a significant challenge. It is also worth recording that there was little appetite or enthusiasm in either North or South Tipperary for the merger. It was suggested by one director that 'the only thing we had in common was our name and our hurling team'. North Tipperary County Council was part of the old Mid-West region and had strong connections with Limerick, which is thirty kilometres from Nenagh. South Tipperary County Council's traditional orientation was to the South-East, in particular Waterford, and to some degree Cork. The culture of the two councils was also very different. However, from the announcement of the merger there was an acceptance among those involved of the political decision and a willingness to overcome challenges in order to implement the merger.

The TRIG made an early decision that both headquarters, in Clonmel and Nenagh, should be retained, albeit with a rationalisation of administrative functions in each location. In order to provide clarity and certainty for all concerned, the implementation plan confirmed the decisions of the TRIG in respect of the service delivery model, structure, and location of directorates in the new council.

Overall, merger planning was very effective. The establishment of the merger implementation team and, in particular, the assignment of a director to work full-time on the project happened at an early stage and were important steps. Intense work was put into the preparation of the TRIG implementation plan, which paid dividends over the entire pre-merger period. The implementation plan also served to reassure staff that there would be no compulsory redundancies or relocations between Clonmel and Nenagh. To the extent that a perception persists that Clonmel 'lost out' to Nenagh in the division of services, notwithstanding the fact that the rationale for decisions with respect to the location of services was included in the implementation plan, it could be concluded that this was not explained to staff as directly as was required. 


\section{Merger implementation}

The merger implementation phase is regarded as the period from the acceptance of the implementation plan in summer 2012 to the official merger date on 3 June 2014. Following the announcement of the local government reforms in Putting People First, the merger project became far bigger and more complex. Whereas previously it had encompassed the merger of the two local authorities and the incorporation of the Tipperary Joint Library Committee, it now also involved the closure of the county's six town councils and borough council, and amalgamation of their staff. ${ }^{1}$ The reforms also resulted in the establishment of five municipal districts. It was suggested by contributors to the research that, as a result of Putting People First, 'the merger project at the end was a much bigger project', that 'the changes in the environment definitely added to the uncertainty as we went along', and that 'ideally you would do the merger of the local authorities and the abolition of town councils separately'.

The merger implementation phase involved a period of very intense work in order to ensure the merger happened on schedule in June 2014. Many aspects of the implementation programme were handled with considerable precision, and in the case of workforce planning it is acknowledged that the process was carefully and sensitively managed. However, given the scale of the project and with the benefit of hindsight, it is not surprising that it is possible to conclude that some aspects of the project could have been managed differently.

There was a good level of awareness of the importance of communication, and a communications strategy was in place from spring 2013. Some staff at the focus groups perceived the approach to communication as being 'top down', with information 'getting lost in the middle'. While understandable in large organisations - and particularly in Tipperary's case, where the two main centres were ninety kilometres apart - the traditional approach of briefing senior managers and depending on them to effectively relay key messages to staff in their sections was perhaps somewhat unreliable given the importance at times of the messages to be communicated. Both staff and senior managers were critical of the over-reliance on emails as a means of communication, particularly in the immediate pre-merger period.

${ }^{1}$ Carrick-on-Suir, Cashel, Nenagh, Templemore, Thurles, Tipperary Town Councils; Clonmel Borough Council. 
Merging systems and procedures at the same time as maintaining service delivery was very challenging. In the final months before June 2014, with a need to put arrangements in place as expediently as possible, a tendency emerged in some sections to adopt the approach of the centre in which the service was headquartered. This is regrettable as it resulted in staff based in the other centre believing that their knowledge and know-how was not being valued.

\section{Merger consolidation}

The implementation plan envisaged the merger project continuing until the end of 2015. However, in practice merger consolidation will continue over many years. The creation of Tipperary County Council was a significant project encompassing both the political merger of the two former councils and the town and borough councils, and the administrative merger of approximately 1,200 staff. As a number of interviewees commented, 'it's important to acknowledge the scale of the thing', and 'survival and business continuity were big achievements'. The merger occurred on schedule, with no negative customer, political or trade union reaction.

Given the scale of the changes involved, adjusting over time to the new reality is important. As noted in a report on public sector mergers by the IBM Center for the Business of Government (2003, p. 5):

Although the implementation stage of the merger should move quickly, the entire merger process requires considerable oversight over a long period of time. Adjustments and adaptations are almost always needed once the first wave of change has settled and it is possible to see the new organisation clearly.

For a majority of staff working in Tipperary County Council, it is the day-to-day realities of their working life that most influence their attitude to the merger. In this regard, a successful merger combines not only the technical aspects of two organisations but also the different cultures. Removing divisions and developing a single culture around a shared understanding of the aims of the new organisation are fundamental to any merger.

For Tipperary, understandably in the months leading up to the merger date and in the immediate aftermath, the primary focus was on business continuity, the needs of customers, the political merger, and systems and procedures. However, in the subsequent months the need 
to address cultural differences has come to the fore and is appreciated by the management and merger teams. As noted by the IBM Center for the Business of Government (2003, p. 5):

Mergers do not involve the simple addition or deletion of agency features. They demand the creation of something new. A critical element in institutionalising change is thus the construction of a new organisational culture, one that is different from any of those existing in any of the merged agencies.

In one respect, there are many similarities between the two former councils in that the services they deliver are the same, and both operate under the same Irish public service and local authority terms and conditions. However, the Tipperary merger encompasses the amalgamation of ten organisations - the two former county councils, the seven town and borough councils and the Joint Library Committee. Thus, there were ten different ways of doing things. It is inevitable that integrating these approaches will take time.

\section{Assessment of the merger}

Notwithstanding the fact that a full assessment of the Tipperary merger will not be possible for a number of years, it is still possible to assess outcomes to date. Examining the merger in the context of the terms of reference provided by the government, it is possible to conclude that the merger has been successful to date in achieving or progressing all of the main objectives.

\section{Deliver the merger effectively and on time}

The establishment of Tipperary County Council happened on schedule on 3 June 2014. Given the scale of the merger project and the number of stakeholders involved, it is the view of the researchers that the merger was managed effectively. That said, there are areas of the planning and implementation of the merger that could have been better.

\section{Maintain delivery of services across the county}

The terms of reference referred to an 'orderly transition to the unified authority, while maintaining effective service delivery'. The merger happened without disruption to service and without the unforeseen closure of any public desks. A number of information campaigns were 
held to inform citizens about the merger, and some initiatives were put in place to accommodate those who might have been disadvantaged, from a services perspective, by the closure of the town councils and area offices. Considerable care was also taken to support elected representatives with regard to the merger.

\section{Maximise resource deployment and savings}

The terms of reference referred to 'actions necessary to maximise cost reductions and efficiencies'. The implementation plan estimated that, once revised staffing levels were reached, gross savings of $€ 6.1$ million a year would be achieved over an extended period. It identified that these would arise primarily from reduced payroll costs, amounting to $€ 4.8$ million. The realisation of these savings is occurring at a faster rate than anticipated by the implementation plan. By February 2015, savings in excess of $€ 3$ million had been achieved. This figure is based on departures since the merger was announced, less those posts refilled with the approval of the Department of the Environment, Community and Local Government.

The costs of the merger included one-off expenditure on IT harmonisation, office improvements and corporate branding, amounting to $€ 1.7$ million, somewhat lower than the anticipated figure. Recurrent costs, occasioned by the harmonisation of corporate rates in the former North Tipperary County Council area to the level that applied in South Tipperary County Council, will be $€ 330,000$ per annum.

\section{Maximise economic development opportunities for the county}

The terms of reference referred to the identification of measures to maximise the capacity of local government to contribute to the economic development of Tipperary as a whole'. The intention in the Putting People First reform initiative is that local government will become significantly more involved in economic planning and development. As a larger authority, well positioned at the centre of the new Southern Region, Tipperary County Council is committed to contributing to the regional economic and spatial strategy once the regional structures are in place. The new corporate plan was adopted by the council in March 2015 and is now available on the council's website. Following the putting in place of the relevant structures, it is anticipated that the local economic and community plan will be published in summer 2015. These plans set the context for enhanced economic and community development in the merged Tipperary County Council. 


\section{Realising the benefits of the merger}

A key driver for the Tipperary merger was cost reduction. However, the implementation plan also referred to benefits for the county from the merger. Over the course of this study, many other opportunities were noted by senior managers and staff. While of value in themselves, realising benefits is also critical to maintaining the morale and commitment of all staff, who in many cases, as identified in the consultation phase of the report, are experiencing merger fatigue.

The old two-council approach within two regional authorities hindered Tipperary's capacity to promote the economic, social and physical development of the county. The new, larger council with greater influence will be in a stronger position to access funding. The county is also now more strategically positioned within the new Southern Regional Assembly and, it is anticipated, will be better able to attract investment.

Promoting the county from a tourism perspective is now a far more coherent proposition and the county is now in a stronger position to take advantage of the worldwide recognition for the name and brand of 'Tipperary'. It is recognised that the combined county has a very good tourism product and can work towards encouraging visitors to stay in the county rather than stop off en route to another overnight destination.

The larger council will be better positioned to take advantage of the new priority within local government for community and enterprise development. It will be possible for staff to move into these functions and ensure that optimum services are delivered for communities and citizens in Tipperary.

For management, the larger complement of staff means that it may take on revenue-generating initiatives such as the management of shared services.

For council staff, the larger organisation will afford greater careerdevelopment opportunities, although these may sometimes be located at the other end of the county. There are opportunities to learn from the expertise of a broader pool of staff, as well as the opportunity afforded by greater staff resources to work on specific projects.

\section{Lessons learned}

The merger of two large public service organisations was not common in Ireland prior to the announcement of the mergers in Tipperary, Limerick and Waterford. For those involved, the process was 
challenging in many respects but also brought opportunities for development. In the course of the consultation for this paper, on a number of occasions learning was identified which is likely to provide guidance to other public service organisations engaged in reorganisation. The suggestions made are also supported by the public management literature around mergers and amalgamations.

The comment most often repeated by those consulted was the importance of resourcing the merger at a very high level. While the commitment and work effort of all line managers is important, in order to ensure normal service is maintained it is essential to place a senior manager full-time on the merger. This person will be supported as needed by the chief executives, human resources, corporate services and other senior managers, but responsibility for the day-to-day oversight of the merger project will reside with him or her.

As with any change-management project, leadership from the top is regarded as critical. The fact that this requires two chief executives and two management teams, quite possibly with different priorities, to work together effectively makes it both more challenging and more necessary. In some respects public service organisations have an advantage in this regard as the concept of public service ethos encompasses a commitment to implementing government policy. However, an open and committed approach is still required. Effective merger leadership also requires a very high degree of involvement and time from the chief executive(s). In this regard, personal effort on the part of the chief executive(s) - for example, visiting staff in all organisation sites - is very worthwhile.

In the case of the Tipperary merger it was suggested that 'communication with staff was good but it could have been better' While challenging in large organisations, efforts to ensure that staff hear messages directly from senior management rather than through a top-down approach, whereby line managers are expected to pass on information, are desirable. Employing many different means of communication, such as staff bulletins and roadshows, is also useful, with emails being only one, perhaps limited, means of communication. Finally, huge time and attention need to be taken to ensure that communications of a personal nature - for example, changes in roles or work locations - are managed in a very sensitive manner. Failures in this regard have the potential to cause huge resentment.

Recognising and addressing cultural differences between the merged organisations have a huge bearing on merger consolidation. In particular, different management styles and different approaches to service delivery will need to be reconciled. Though it takes time and 
energy, it is important that neither organisation's way of doing things is imposed on the other organisation, but that instead a new way of doing things emerges which draws on the best of both.

'Harnessing the support and goodwill of staff' is regarded as a key success factor in Tipperary. Involving staff at all levels in the project as required - as early as possible is recommended - will contribute to higher levels of engagement with the idea of the merger. Identifying key staff and giving them responsibility for delivering on specific merger projects will be essential during the merger implementation phase. Finally, recognising the considerable work effort and contribution of staff is essential for merger consolidation.

\section{Concluding comments}

One of the most significant comments made by a director in discussing opportunities afforded by the merger was that 'there is an appetite to go after benefits'. However, it is essential that this commitment is held not just by the chief executive and directors but by all council staff. Ensuring that this is the case involves acting on the feedback and recommendations set out in this paper - that is, addressing general work-related issues, dealing with specific problems that may arise in a small number of sections, and supporting a new, unified culture. Celebrating the merger and identifying and recognising significant contributions are also important.

Ultimately, as noted in a report by Cranfield University School of Management (2002, p. 57), it also helps to understand that there is no 'quick fix' in respect of merger consolidation and 'in this context the tribulations and difficulties which you may encounter along the road may seem tolerable'. The report concluded by noting that 'you can achieve your vision but how quickly depends on how you manage the process. You start out with a merger and end, perhaps many years forward, with a new organisation and a new culture.'

\section{Acknowledgements}

This article is based on a review of the Tipperary County Council merger that the IPA's research division was asked to carry out by the Tipperary management team in autumn 2014. The resulting report was published by the Institute in June 2015 and is available at www.ipa.ie/research. The author wishes to acknowledge the input and helpful comments of Sean Keating, Director of Service with responsibility for the merger at Tipperary County Council. 


\section{Appendix 1:}

Fact sheet on Co Tipperary, Tipperary County Council and the two former administrative areas

\begin{tabular}{lcrc}
\hline Measure & $\begin{array}{c}\text { Former } \\
\text { North } \\
\text { Tipperary } \\
\text { County } \\
\text { Council }\end{array}$ & $\begin{array}{c}\text { Former } \\
\text { South } \\
\text { Tipperary } \\
\text { County } \\
\text { Council }\end{array}$ & $\begin{array}{c}\text { Tipperary } \\
\text { County } \\
\text { Council } \\
(2015 \\
\text { figures) }\end{array}$ \\
\hline Population (2011 Census) & 70,322 & 88,432 & 158,754 \\
Area $\left(\mathrm{km}^{2}\right)$ & 2,024 & 2,258 & 4,282 \\
Revenue budget 2014 (€ million) & 61.37 & 64.84 & $138.66^{*}$ \\
Capital budget 2014 (€ million) & 7.12 & 9.41 & 34.64 \\
Commercial rate (2012) & 59.525 & 56.77 & 56.77 \\
No. of staff, end March 2012 (WTE*) & 478 & 614 & $1,002^{* *}$ \\
Retained firefighters, March 2012 & 72 & 61 & 131 \\
Elected members (No.) 2014 & 21 & 26 & 40 \\
Electoral areas (No.) 2014 & 4 & 5 & 5 \\
Km of road & 2,728 & 2,859 & 5,587 \\
Km of water main & 1,413 & 2,100 & 3,513 \\
No. of LA-owned dwellings (2014) & 1,107 & 1,357 & $4,702^{*}$ \\
\hline
\end{tabular}

* Including former Clonmel Borough Council and six town council administrative areas.

** In accordance with Department of the Environment, Community and Local Government return criteria. 


\section{Appendix 2:}

\section{The new Tipperary County Council administrative region}

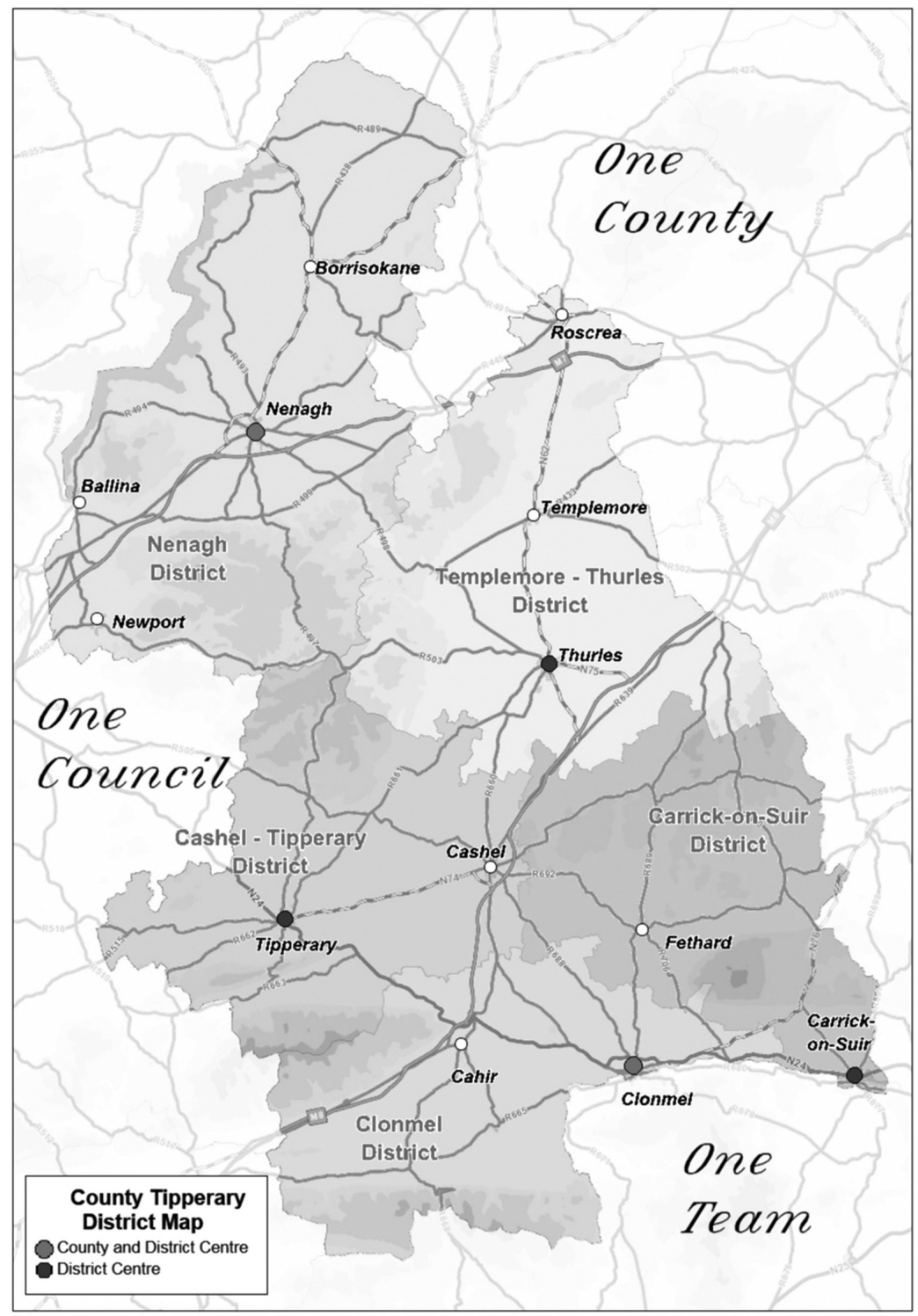




\section{References}

Boyle, R. (2015). Overview of selected international experience with local government reorganisation, mergers and amalgamation. Dublin: IPA.

Cranfield University School of Management. (2002). Growing together: Managing trade union cooperation and merger. Retrieved from http://www.ilo.org/public/english/staffun/info/meetings/international/gva09 05/growing.pdf [1 May 2015].

Department of the Environment, Community and Local Government. (2012). Putting people first: Action programme for effective local government. Retrieved from http://www.environ.ie/en/PublicationsDocuments/File DownLoad, 31309,en.pdf [1 May 2015].

Dollery, B., \& Kortt, M. (2013). Bigger is not always better: An evaluation of future prosperity of the Hawkes Bay region and potential costs and savings of local government reform in Hawkes Bay. Retrieved from https:/www.fndc.govt.nz/your-council/local-government-reorganisation/ files-2014-01-17/Napier-City-Council-commissioned-Bigger-is-not-alwaysbetter-Dollery-report-November-2013.pdf [1 May 2015].

Government of Ireland. (2010). Report of the Local Government Efficiency Review Group. Retrieved from http://www.environ.ie/en/LocalGovern ment/ PublicationsDocuments/FileDownLoad,23533,en.pdf [1 May 2015].

Grant Thornton. (2010). Implementing mergers and consolidation across the public sector: The hard work's only just beginning. Retrieved from http://www.grant-thornton.co.uk/PageFiles/3804/Public_Sector_Report_ 2010.pdf [1 May 2015].

IBM Center for the Business of Government. (2003). Making public sector mergers work: Lessons learnt. Retrieved from http://www.businessof government.org/sites/default/files/PublicSectorMergers.pdf [1 May 2015]. 